\title{
Drug Utilization Study in Ophthalmology Outpatient Department of a Tertiary Care Teaching Hospital
}

\author{
Sarfaraz Mohammed*, Aksa Maria Thomas, Anju Joy, Annura Ann Abraham, Devathi Sravya, \\ Doddayya Hiremath
}

Department of Pharmaceutics, NET Pharmacy College, Raichur, Karnataka, INDIA.

\begin{abstract}
Background: World Health Organization (WHO) has defined drug utilization in 1977 as marketing, distribution, prescription and use of drugs in a society with special emphasis on the resultant medical and social consequences. It should be evaluated periodically to increase the therapeutic efficacy and decrease adverse effects. Objectives: The aim of study is obtain data on the current prescribing pattern and drug utilisation trend of ophthalmologist in a tertiary care teaching hospital with ultimate goal to promote appropriate use of drugs. Methods: This prospective interventional study was conducted in 272 patients of either sex visiting Ophthalmology outpatient department over a period of six months at $\mathrm{NMCH}$ and $\mathrm{RC}$, Raichur, Karnataka. The data collected from data collection form was analysed with the help of WHO prescribing indicators and evaluated using descriptive statistics. Results: Prescription analysis showed that the average number of drugs per prescription was 2.45. Drugs were mostly prescribed by brand name $(98.5 \%)$, Eye drops $(69 \%)$ were most prescribed dosage form, Injections $(0.75 \%)$ were least prescribed, drugs prescribed from Essential Drug List was $50.9 \%$. Antibiotics were most prescribed class of drugs (49.62\%). Dosage form, frequency and duration of therapy were recorded in $100 \%, 95.5 \%$ and $84 \%$ of prescriptions. Conclusion: Polypharmacy was slightly seen in prescriptions. Antibiotics were highly used. The most commonly prescribed dosage form was eye drops. Half of drugs were prescribed from Essential drug list (EDL). Physicians preferred branded drugs rather than generic drugs. Diagnosis of the patient was not recorded for most of the prescriptions.
\end{abstract}

Key words: Drug utilization evaluation, WHO core drug prescribing indicators, Polypharmacy, Generic name, Ophthalmology.

\section{INTRODUCTION}

World Health Organization (WHO) has defined drug utilization in 1977 as marketing, distribution, prescription and use of drugs in a society with special emphasis on the resultant medical and consequences. ${ }^{1} \mathrm{It}$ should be evaluated from time to time so as to increase the therapeutic efficacy and decrease adverse effects. ${ }^{2}$ Drug Utilization Study is important to realize that, inappropriate use of drugs represent a potential hazard and an unnecessary expense to the patients. ${ }^{1,3-6}$ Inappropriate uses of medications include over- or under-usage of drugs, high medication prices, indiscriminate and repeated use of injections and antibiotics, use of multiple medicines, use of brand name instead of generic name in prescribing and non-prescribing medicines that may not agree nor comply with standard guidelines or from EDL are major medical practice concerns. The consequences of these include ineffective treatment, development of antimicrobial resistance (AMR), adverse effects and economic burden on patients and society. ${ }^{7,8}$

Assessment of drug use patterns with WHO drug use indicators is becoming increasingly necessary in developing countries to promote appropriate drug use. A small number of basic indicators are indicated which are referred to as the core indicators. These are highly standardized do not need national adaptation and are recommended for inclusion in any drug use study using indicators. ${ }^{1}$

Ophthalmology is a branch of medicine and surgery which deals with the diagnosis and treatment of eye disorders. ${ }^{9}$ In
DOI: 10.5530/ijopp.14.3.33

Address for correspondence: Dr. Sarfaraz Md Professor, Department of Pharmaceutics, NET Pharmacy College, Raichur-584103, Karnataka, INDIA.

Phone no: +91 9448711094 Email Id: sarfindia@gmail.com

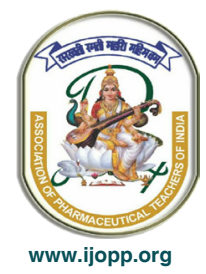


ophthalmology recently, many drug advances and modern ocular therapeutic medications are introduced. Various heterogenic classes of drugs are used in the treatment of ophthalmologic diseases. ${ }^{10,11}$ Therefore, in ophthalmology practice, rational prescribing plays a key role in reducing the burden of ocular disease. Optimum management of ocular disease has large impact in prevention of loss of vision. ${ }^{12}$

In India, literature studies in Ophthalmology had shown issues of poor selection and prescribing of essential drugs and generic medicines. ${ }^{13}$ Keeping these facts in consideration, the study was intended to obtain knowledge on the prescribing pattern and drug utilization trend in ophthalmology department at a tertiary care teaching hospital with ultimate goal to promote rational use of drugs among prescribers.

\section{MATERIALS AND METHODS}

This prospective interventional study was conducted for a period of six months from September 2019 to February 2020 in Navodaya Medical College, Hospital and Research Centre (NMCH and RC) Raichur. Permission was obtained from ethical clearance committee before the beginning of study (NETPC/IAEC/2019/12). A total of 272 prescriptions were collected during the study period. The project team collected demographic details, medical history, medication details and diagnosis of eligible patients in an appropriately designed data collection form on daily basis from the outpatient Ophthalmology department of hospital. Concurrent study was performed in patients of either sex and all age groups who visited outpatient department of Ophthalmology. All the new cases with drug prescription were included in the study. Patients who were not prescribed with any drug but underwent other interventional procedures and with follow-up cases were omitted. All the collected data were analysed with the help of WHO prescribing indicators and the data was evaluated using descriptive statistics.

\section{RESULTS}

Out of 272 patients included in the study, 148 were females and 128 were males. Figure 1 shows the age distribution of study participants. The age group ranged from 2 to 88 yrs. In about 247 prescriptions, 667 drugs were prescribed. The drugs were prescribed in various dosage forms. Figure 2 indicates the types of dosage forms prescribed in study participants. The most prescribed dosage type was eye drops $(69 \%)$, followed by tablets $(23.8 \%)$ and eye ointments $(5.39 \%)$. Among 272 prescriptions, the most frequently prescribed drugs were Carboxymethyl cellulose (CMC) in 95 (34.92\%) prescriptions, followed by Moxifloxacin in 75 (27.57\%), Ciprofloxacin in 59 (21.69\%), Natamycin in $24(8.82 \%)$ and Olopatadine in $34(12.5 \%)$ prescriptions respectively. Figure 3 shows different percentages of most frequently prescribed drugs.

Fixed Dose Combinations (FDC) was prescribed in $74.2 \%$ of patients. Table 1 presents the most frequently prescribed Fixed Drug Combinations in study participants. The most frequently prescribed FDC's were Ofloxacin + Dexamethasone in $77(28.3 \%)$ patients followed by Ibuprofen + Paracetamol in 37 (13.60\%), Ofloxacin + Ketorolac in $36(13 \%)$ and Polymixin B + Chloramphenicol in 19 (6.98\%) patients.

Out of 667 drugs, it was observed that 16 therapeutic drug classes were prescribed by the physicians. Among all the therapeutic drug classes antibiotics 331 (49.62\%)

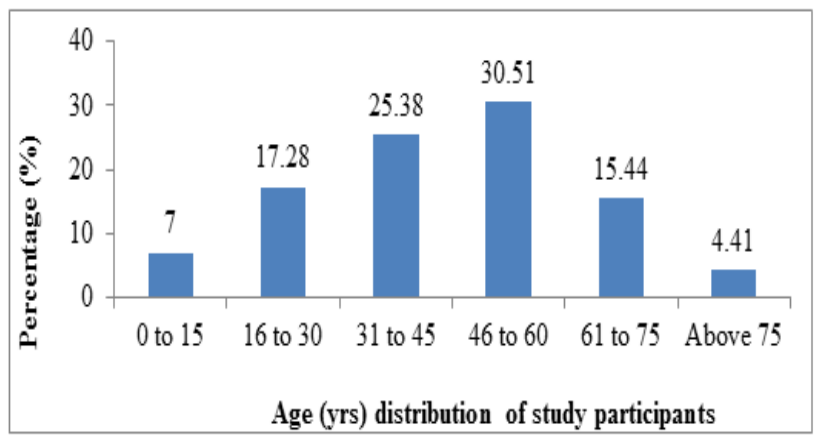

Figure 1: Age (yrs) distribution of study participants ( $n=272)$.

\begin{tabular}{|c|c|c|}
\hline $\begin{array}{l}\text { Fixed Drug } \\
\text { Combinations }\end{array}$ & $\begin{array}{c}\text { No. of } \\
\text { prescriptions } \\
(n=272)\end{array}$ & $\begin{array}{l}\text { Percentage } \\
\quad(\%)\end{array}$ \\
\hline $\begin{array}{c}\text { Ofloxacin+ } \\
\text { Dexamethasone }\end{array}$ & 77 & 28.3 \\
\hline Ofloxacin+ Ketorolac & 36 & 13 \\
\hline $\begin{array}{l}\text { Polymyxin } \mathrm{B}^{+} \\
\text {Chloramphenicol }\end{array}$ & 19 & 6.98 \\
\hline Ibuprofen+ Paracetamol & 37 & 13.60 \\
\hline $\begin{array}{c}\text { Diclofenac+ } \\
\text { Serratiopeptidase }\end{array}$ & 12 & 4.41 \\
\hline Gatifloxacin+ Ketorolac & 7 & 2.57 \\
\hline $\begin{array}{l}\text { Aceclofenac+ } \\
\text { Paracetamol }\end{array}$ & 2 & 0.73 \\
\hline $\begin{array}{l}\text { Gatifloxacin + } \\
\text { Flurbiprofen }\end{array}$ & 8 & 2.94 \\
\hline Dorzolamide + Timolol & 4 & 1.47 \\
\hline
\end{tabular}


were mostly prescribed, followed by lubricants 109 (16.34\%), NSAID's 62 (9.29\%), Antihistamines 36 (5.39\%), Corticosteroids 29 (4.34\%), Anti-cholinergic 22 (3.29\%), Proton pump inhibitors 16 (2.39\%), CAI 14 (2.09\%), H2RA 13 (1.94\%), Anti-inflammatory 12 $(1.79 \%)$, Beta blockers $8 .(1.19 \%)$, Immunosuppressants 7 (1.04\%), Antiviral 4 (0.59\%), Multivitamin 2(0.29\%), Leukotriene inhibitors $1(0.45 \%)$ and antifungal at the rate of $1(0.45 \%)$. Figure 4 illustrates the different therapeutic drug classes prescribed.

The commonly prescribed Antibacterial Classes in study participants are depicted in Figure 5. Fluoroquinolones $(81 \%)$ were the most commonly prescribed group of antibiotics.

The information about the frequency of drug administration was present in $95.58 \%$ of drugs and duration of drug therapy was recorded in $84 \%$ of the drugs prescribed and dosage form was recorded in 100 $\%$ of the drugs. However 10 prescriptions $(2.20 \%)$ were containing the clinical diagnosis of the patients (Table 2).

Prescriptions were analysed using WHO indicators to explain the current trend of prescribing pattern and drug utilization in the hospital. (Table 3). The average number of drugs per prescription was 2.45. Figure 6 shows the distribution of drugs per prescription. The number of drugs was observed to be from one to six per prescription.

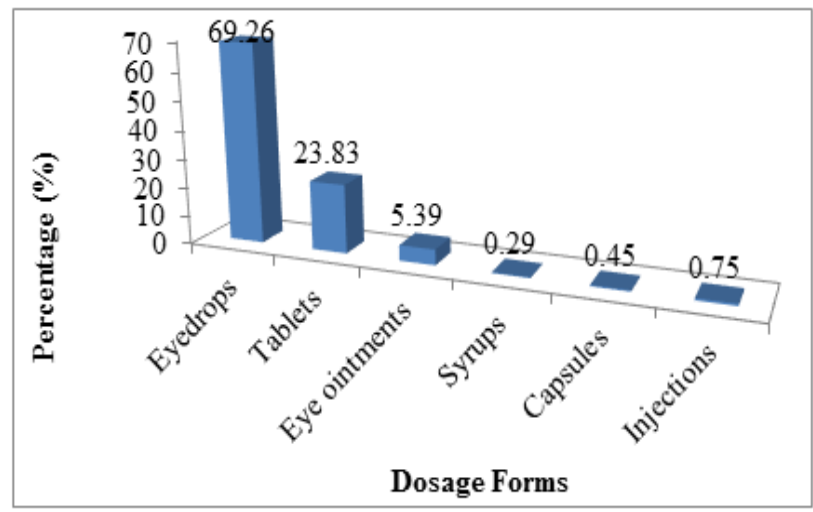

Figure 2: Types of Dosage Forms prescribed in study participants $(n=667)$.

\begin{tabular}{|cc|}
$\begin{array}{l}\text { Table 2: Drug Utilisation Parameters used to analyse } \\
\text { study prescriptions }(\boldsymbol{n = 2 7 2 ) .}\end{array}$ \\
\hline Drug Utilisation Parameter & Study value (\%) \\
\hline Frequency of therapy recorded & 95.58 \\
Duration of therapy recorded & 84 \\
Dosage form recorded & 100 \\
Diagnosis recorded & 2.205 \\
\hline
\end{tabular}

One drug was prescribed in $48(17.64 \%)$ prescriptions, two drugs in 114 (41.91\%), three drugs in $65(23.89 \%)$, four drugs in 30 (11.03\%), five drugs in $13(4.78 \%)$ and six drugs in 2 prescriptions $(0.73 \%)$. About $1.17 \%$ of drugs were prescribed by generic name. Antibiotics were frequently prescribed and percentage of encounters with antibiotic was $86 \%$. About $1.47 \%$ patients had encounters with a prescribed injection. The drugs prescribed from the EDL were about $50.9 \%$.

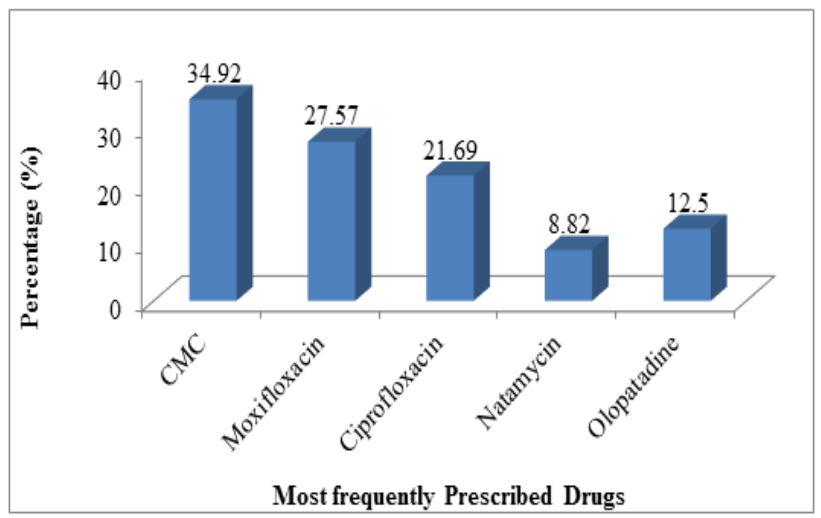

Figure 3: Most frequently prescribed drugs in study participants $(n=272)$.

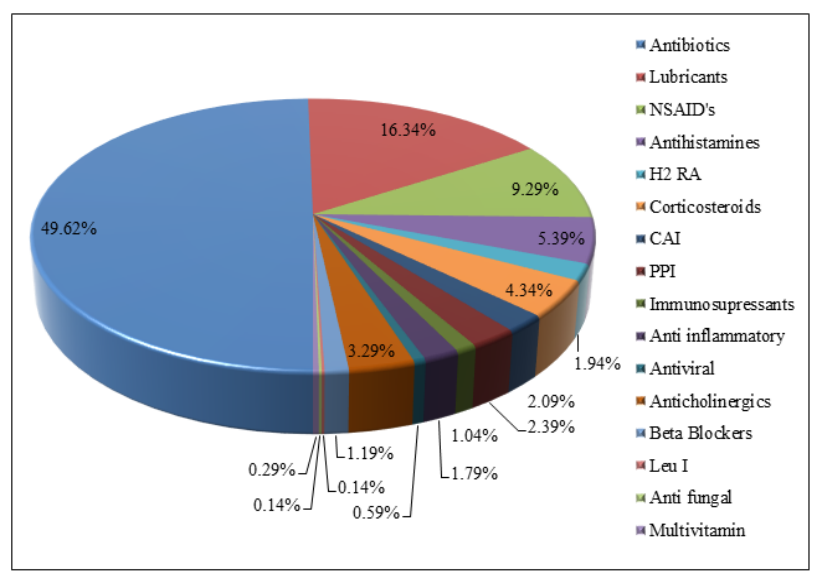

Figure 4: Pie chart showing Prescribed Therapeutic drug classes in study participants $(\mathrm{N}=667)$.

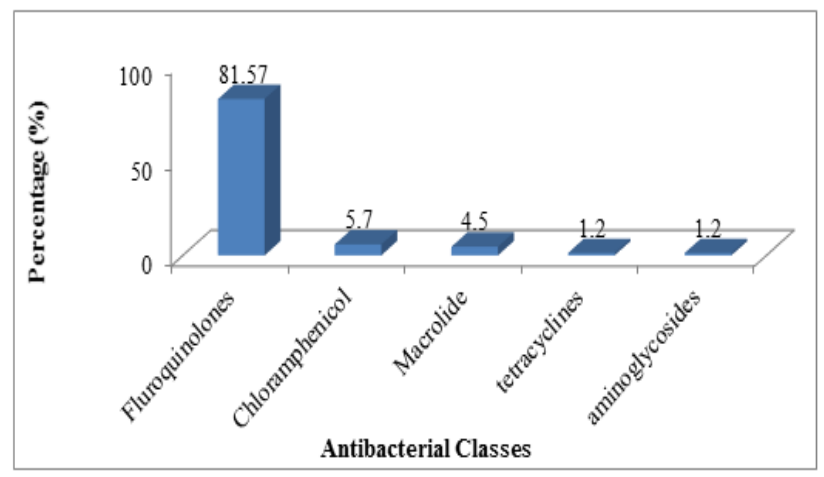

Figure 5: Commonly prescribed antibacterial classes in study participants $(\mathrm{N}=331)$.

Indian Journal of Pharmacy Practice, Vol 14, Issue 3, Jul-Sep, 2021 
Table 3: WHO core drug prescribing indicators used to assess study prescriptions ( $n=272$ ).

\begin{tabular}{|c|c|c|c|}
\hline $\begin{array}{l}\text { Sl. } \\
\text { No. }\end{array}$ & WHO Indicators & $\begin{array}{l}\text { Standard } \\
\text { Value }\end{array}$ & $\begin{array}{l}\text { Study } \\
\text { Value }\end{array}$ \\
\hline 1 & $\begin{array}{l}\text { Average number of drugs per } \\
\text { prescription }\end{array}$ & $1.6-1.8$ & 2.45 \\
\hline 2 & $\begin{array}{l}\text { Percentage of drugs prescribed } \\
\text { by generic name (\%) }\end{array}$ & 100 & 1.17 \\
\hline 3 & $\begin{array}{l}\text { Percentage of encounters with } \\
\text { an antibiotic prescribed (\%) }\end{array}$ & $20-26.8$ & 86 \\
\hline 4 & $\begin{array}{l}\text { Percentage of encounters with } \\
\text { an injection prescribed }(\%)\end{array}$ & $13.4-24.1$ & 1.47 \\
\hline 5 & $\begin{array}{l}\text { Percentage of drugs prescribed } \\
\text { from Essential Drug List (\%) }\end{array}$ & 100 & 50.9 \\
\hline
\end{tabular}

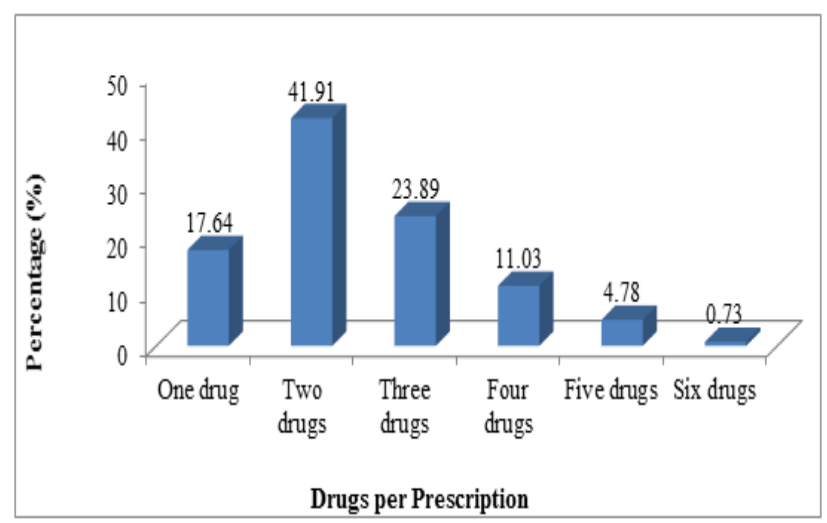

Figure 6: Distribution of drugs per prescription in study participants $(n=272)$.

\section{DISCUSSION}

Misuse of drugs is quite common throughout the world due to irrational prescribing, dispensing and administration of medications. In this perspective drug utilization studies are very helpful in promoting the rational use of drugs in population. It also emphasizes the need for periodic review and educational interventions in prescribing practices. The present study was an attempt to explain the current trend of prescribing pattern and drug utilization in Ophthalmology OPD in Navodaya Medical College, Hospital and Research Centre (NMCH and RC), Raichur; a tertiary care center, with an intention to promote proper use of drugs among prescribers.

A total of about 272 prescriptions were reviewed from the outpatients of Ophthalmology department. Out of 272 patients, 148 (54\%) were female and $124(46 \%)$ were male. This result was similar to studies carried out by Rawah MA et al. ${ }^{14}$ and Prathap SA et al. ${ }^{15}$ and on the contrary, studies done by Slathia A et al. ${ }^{16}$ and Dhami $\mathrm{DB}$ et al. ${ }^{17}$ showed that men were more prone to Ocular diseases than women. Hence these findings conclude that the eye diseases are not usually sex linked. After certain age both genders are at higher risk for the ocular diseases because of age related macular degeneration and cataracts.

Age was taken into consideration from the prescriptions collected, by dividing into 6 age groups being kept an interval of $15 \mathrm{yrs}$ each (Figure 1). Maximum number of patients were found in the age group of 46-60 yrs (30.51\%), followed by $31-45$ yrs $(25.38 \%), 16-30$ yrs $(17.28 \%)$, and $61-75 \mathrm{yrs}(15 \%)$. The data suggested that middle aged and older adults were at higher risk. This is probably due to age related macular degeneration, decreased tear production, suppressed immune system causing more infections, certain medical conditions such as Diabetes, hypertension and side effects of drugs. This result was similar to the study done by Suman RK et al. ${ }^{18}$

A review of all prescriptions revealed that various dosage forms were prescribed for the patients (Figure 2). Out of 272 prescriptions containing 667 drugs, majority were in the form of eye drops 462 (69.3\%), followed by tablets 159 (23.83\%), eye ointments $36(5.39 \%)$. The findings were similar to study done by Biswas NR et al. ${ }^{2}$ This showed most of the drugs used were topical preparations. It was evident that use of topical preparations such as eye drops and ointments for treating eye disease is effective as they have site specific action, systemic administration with fewer side effects and moderate systemic absorption. Compared to eye drops, ointments were prescribed very less because only few antibiotics are formulated into ointments and majority of ointments have side-effects.

The most frequently prescribed drugs were $\mathrm{CMC}$ in 95 $(34.92 \%)$ prescriptions, followed by Moxifloxacin in 75 (27.57\%), Ciprofloxacin in $59(21.69 \%)$, Natamycin in $24(8.82 \%)$ and Olopatadine in $34(12.5 \%)$ prescriptions respectively (Figure 3). This finding had a similarity with the previous study done by Yasmeen $\mathrm{M}$ et al. ${ }^{19}$ Globally, the leading cause of eye disorders is infection, dry eye syndrome, loss of vision and aging. Data collected for the study indicated that higher number of patients reported with complaints of dry eyes, itching, redness and presence of foreign body. So, the above drugs were prescribed commonly by the physician as they help in relieving the symptoms. CMC is the most frequently prescribed drug because it helps in treating dry eyes by increasing tear production and protects the ocular surface from desiccation, allows prolonged retention time and increases moist nature of eyes. Moxifloxacin, Ciprofloxacin and Natamycin are the frequently given antibiotics. Based on the microorganism that caused infection and type of foreign substance present in the eye physician decides which class of antibiotics should be prescribed. These drugs were preferred more in this study as they do not develop resistance and have a broad 
spectrum of activity against both gram negative as well as gram positive organisms with less side effects.

Olopatadine is an antihistamine which reduces allergy by blocking $\mathrm{H} 1$ receptors. Olopatadine shows rapid action in suppressing allergy compared to remaining antihistamines and hence prescribed commonly.

Fixed dose combinations (FDCs) were prescribed in $74.2 \%$ of patients (Table 1). This suggests the increasing use of FDCs in modern ophthalmic practice. The most often prescribed FDC was Ofloxacin plus dexamethasone eye drop (28.3\%), followed by Ibuprofen plus paracetamol $(13.60 \%)$ tablet, Ofloxacin plus ketorolac (13\%) eye drop and Polymixin B plus chloramphenicol (6.98\%) eyedrop. It was observed that antibiotics were mostly given in combination with corticosteroids and NSAID's. The combination of antibiotic with corticosteroid or NSAID is effective in controlling inflammation and relieving pain. FDCs should be used only when necessary because inappropriate use of FDC's can lead to increased adverse drug reactions (ADR's) and financial burden to patients. Results obtained in this study were in contrast to that published by Prajapathi and Yadav. ${ }^{20}$

Out of 667 drugs, it was observed that 16 therapeutic drug classes were prescribed by physicians (Figure 4). Among all the therapeutic drug classes antibiotics 331 $(49.62 \%)$ were mostly prescribed which is supported by study conducted by Jadhav PR et al. ${ }^{21}$ Antibiotics were prescribed alone and also as FDC's. The most frequently prescribed antibiotic as mono therapy was Moxifloxacin (27.57\%), which was also the most commonly prescribed drug. The highly prescribed combination was Ofloxacin + Dexamethasone $(28.3 \%)$ and was also the most frequently prescribed FDC.

Inadequate sanitation and severity of infection results in excessive use of antibiotics. It was observed that antibiotics were prescribed empirically in case of infection, corneal ulcer and non-specific symptoms. Fluoroquinolones were the first choice of drugs in bacterial infections and corneal ulcers initially, which justifies use of Moxifloxacin in the Ophthalmology department.

Ocular lubricants $(16.34 \%)$ were the second most prescribed class of drugs and the most commonly recommended lubricant was CMC (34.92\%). Ocular lubricants were prescribed as most patients reported complaints of dry eyes. CMC helps in treating dry eyes by increasing tear production and also prolongs retention time in ocular surface resulting in moistening of eyes and protects the ocular surface from desiccation.
Besides antibiotics, NSAID's (9.29\%) and steroids (4.34\%) were also more prescribed. Among NSAIDs, the most prescribed drug as monotherapy and even as FDC was Ibuprofen (13\%). The most commonly advised corticosteroid was Dexamethasone (28.3\%), as monotherapy as well as FDC. These drugs were prescribed to control inflammation which is usually associated with infectious condition of eye and inflammatory diseases of eye lids. They are used for relief of pain and swelling.

Other class of drugs prescribed like Antihistamines (5.39\%), Anti-cholinergic (3.29\%), Proton pump inhibitors (2.39\%), Carbonic Anhydrase Inhibitors $(2.09 \%)$, Histamine type-2 receptor antagonists 13 $(1.94 \%)$, Anti-inflammatory $(1.79 \%)$, Beta blockers $(1.19 \%)$, Immunosuppressant's (1.04\%), Antiviral $(0.59 \%)$, Multivitamin $(0.29 \%)$, Leukotriene inhibitors $(0.45 \%)$ and antifungal $(0.45 \%)$ show the usage pattern of drugs in ophthalmology department based on patient reported symptoms.

Fluoroquinolones $(81.57 \%)$ were the most prescribed class of antibacterial (Figure 5); this was similar to reports published by Prajwal P et al. ${ }^{22}$ Moxifloxacin, ciprofloxacin, natamycin and ofloxacin were most prescribed fluoroquinolones as they have a broad spectrum of action against both gram negative as well as gram positive organisms with less side effects. The remaining classes of antibiotics were prescribed to less extent.

Drug utilization parameters (Table 2) were used to analyze study prescriptions. The periodicity of drug administration and therapeutic duration are the two key parameters which, if not clearly written or advised, can lead to indiscriminate and inappropriate use of drugs. Results showed that the information about the frequency of drug administration was present in $95.58 \%$ of drugs and duration of drug therapy was recorded in $84 \%$ of the drugs prescribed. Drugs for which dosage formulation, recorded were $100 \%$. Similar pattern was seen in a study conducted at New Delhi by Biswas NR et al. ${ }^{2}$ This revealed good knowledge of the ophthalmologists of institute regarding drug and drug prescribing. However, in the prescriptions, clinical diagnosis was recorded only in $2.20 \%$ of the patients. From collected data, it was observed that nearly $60 \%$ of the patients presented with complaints of dry eyes, vision changes and as they are common eye problems they may not need specific diagnosis. But patients who have infections, symptoms of swelling, itching also remained undiagnosed which shows a need for improvement in prescription writing. As recording of diagnosis is important parameter for proper rational treatment.

Indian Journal of Pharmacy Practice, Vol 14, Issue 3, Jul-Sep, 2021 
The WHO core drug prescribing indicators (Table 3) were used to assess efficiency of health professionals in numerous key aspects related to the proper use of drugs in ambulatory environment. Of the 272 prescriptions containing 667 drugs studied, number of drugs was observed to be from one to six per prescription (Figure 6). This serves as a measure of degree of polypharmacy. As per WHO the average number of the drugs per prescription should be 1.6 to 1.8 . Here it was 2.45 which show polypharmacy. Earlier study done at New Delhi by Biswas NR et al. ${ }^{2}$ reported higher number of drugs per prescription (3.03), while studies done at Rajasthan (2.23) by Prajapati VI, Yadav $\mathrm{AK}^{20}$ and Mumbai (1.9) by Bhatt JH et al. ${ }^{23}$ showed lower number of drugs per prescription. The number of medications per prescription should be kept as low as possible in order to minimize the risk of adverse effects, medication interactions, treatment cost and increased bacterial resistance.

About $1.17 \%$ of drugs were prescribed by generic name. This showed greater tendency to prescribe drug by brand name and influence of the pharmaceutical companies over prescribers. Prescription by the generic name could facilitate cheaper treatment for the patients. Physicians may have been unwilling to prescribe medicines by generic name probably because it can lead to the purchasing of variable potency drugs and lower potent generic antibiotics which may contribute to drug resistance and instability in clinical response. The results obtained were contrary to study done by Bhatt JH et al. ${ }^{23}$ where $42.6 \%$ of medications were prescribed by generic name.

Around $86 \%$ patients had encounters with an antibiotic prescribed, which was higher compared to studies done by Vanya HV et al. ${ }^{13}$ and Bhatt $\mathrm{JH}$ et al. ${ }^{23}$ which showed lower values $(62.2 \%, 32.6 \%)$. It may be due to poor sanitation in our area which leads to higher prevalence of the infective diseases of the eyes, poor education, dry environment and less awareness. Antibiotics were prescribed empirically in the department in cases of infection, corneal ulcer and non-specific symptoms which was appropriate. It also showed that most of the antibiotics were administered topically as drops and ointments thus minimizing adverse effects. Otherwise inappropriate use of the antibiotics will result in higher adverse events and increased risk of bacterial resistance to the antimicrobial agents.

About $1.47 \%$ prescribed drugs showed encounters with an injection, which were only three prescriptions with injections of multivitamins. Results were similar to study done at Rajasthan by Prajapati and Yadav. ${ }^{20}$ Since the analysis was carried out in an ambulatory environment, there was less chance of prescribing injections because most of the patients come with nonspecific symptoms, bacterial infections and vision problems for which topical therapy is given primarily.

The findings revealed that the EDL prescribed medicines were just $50.9 \%$, lower than the standard value given by WHO i.e., $100 \%$, but showed a greater value in contrast to the reports published by Akram MF et al. ${ }^{24}$ Use of EDL drugs should be encouraged for the purpose of optimal use of medications for maximal safety and thereby fulfilling the needs of health care of majority of population.

\section{CONCLUSION}

The study findings concludes that prescribing pattern observed at the study hospital was nearly in accordance with accepted norms of ocular management, as the drugs selected were based on the symptoms of the patients. Eye drops were the preferred topical therapy. Antibiotics were the mostly prescribed class of drugs as mono therapy and combination as well. Drug use evaluation utilizing WHO core drug prescribing indicators showed that polypharmacy was slightly seen in prescriptions, use of injections was limited, majority of the drugs prescribed were antibiotics and half of the drugs were prescribed from EDL. Although the prescriptions in terms of dosage, length, and formulation were completely written, it is important to resolve the lack of reported diagnosis in the prescriptions. The study findings indicated that there is a need for improvement by ophthalmologists in promoting the progress of choosing drugs from EDL and prescribing drugs by generic name. The research shows a need for proper sensitization of physicians, which can be accomplished in the practice of ethical prescribing by continuous medical education and drug audits via shortterm training sessions at periodic intervals. Many such studies need to be done at regular intervals because a large number of prescriptions can be audited to identify early signs of irrational usage of medicines.

\section{ACKNOWLEDGEMENT}

Authors take it as a privilege to acknowledge Sri S. R. Reddy: Chairman, Navodaya Educational Trust, Medical Superintendent; Navodaya Medical College Hospital and Research Centre, HODs of department of Pharmacy practice and Medicine department and the staffs for their support during the study. Special thanks to Mr. Bhaskar, Biostatician and Dr. Anupama, HOD of Ophthalmology Department NMCH and RC, for their valuable guidance and suggestions throughout our project work. 


\section{CONFLICT OF INTEREST}

The authors declare no conflict of interest.

\section{ABBREVIATIONS}

WHO: World Health Organization; EDL: Essential Drug List; AMR: Anti Microbial Resistance; CMC: Carboxy Methyl Cellulose; FDC: Fixed Dose Combinations; NSAIDs: Non-Steroidal Anti-Inflammatory Drugs; CAI: Carbonic Anhydrase Inhibitor; $\mathbf{H}_{2} \mathbf{R A}: \mathrm{H}_{2}$ Receptor Antagonist; OPD: Out-Patient Department; ADR: Adverse Drug Reaction.

\section{SUMMARY}

This prospective study assessed the drug utilization and prescribing patterns in Ophthalmology outpatient department in a tertiary care teaching hospital. By conducting such studies, we can know about the patterns and quality of use of medicines, the determinants of drug use, and the outcomes of use. WHO drug use indicators are highly standardized forms for inclusion in drug utilization studies. Drug utilization studies will increase the awareness among physicians about essential drug concept and use of standard treatment guidelines to encourage the rational drug utilization and reduce the economic burden and provide quality treatment to patients.

\section{REFERENCES}

1. World Health Organization. Action programme on essential drugs and vaccines. How to investigate drug use in health facilities: Selected drug use indicators. World Health Organization. 1993|. https://apps.who.int/iris/ handle/10665/60519

2. Biswas NR, Jindal S, Siddiquei MM, Maini R. Patterns of prescription and drug use in ophthalmology in a tertiary hospital in Delhi. Br J Clin Pharmacol. 2001;51(3):267-9.

3. Dukes MNG. Drug utilization studies: methods and uses. World Health Organization Regional Publications. European series; 45. Copenhagen, Denmark. 1993. http://apps.who.int/medicinedocs/documents/s21868e n/ s21868en.pdf.

4. World Health Organization. Introduction to drug utilization research. Oslo, Norway: WHO; 2003. http://apps.who.int/medicinedocs/en/d/Js4876e/
5. Lee D, Bergman U. Studies of drug utilization. In: Storm LB, editor. Pharmacoepidemiology. Chichester, UK: John Wiley and Sons. 2005;401-17.

6. Rubin RJ, Altman WM, Mendelson DN. Health care expenditures for people with diabetes mellitus, 1992. J Clin Endocrinol Metab. 1994; 78(4):809A-F.

7. Anita H. Confronting III Health: Medicines, Self-Care and the poor in Manila. Quezon-City, Philippines: Health Action Information Network; 1991.

8. Berger M, Murugi J, Buch E, IJsselmuiden C, Kennedy A, Moran M, et al. Strengthening pharmaceutical innovation in Africa. Council on Health Research for Development (COHRED); New Partnership for Africa's Development (NEPAD). 2009.

9. https://en.m.wikipedia.org/wiki/ophthalmology

10. Duggirala A, Joseph J, Sharma S, Nutheti R, Garg P, Das T. Activity of newer fluoroquinolones against gram-positive and gram-negative bacteria isolated from ocular infections: An in vitro comparison. Indian J Ophthalmol. 2007;55(1):15-9.

11. Leonardi A. Emerging drugs for ocular allergy. Expert Opin Emerg Drugs. 2005;10(3):505-20.

12. Able RS, Able AD. Ocular diseases: In Avery's drug treatment. $4^{\text {th }}$ ed. Auckland: Adis International: 1997.

13. Vaniya HV, Darji NH, Patel VR, Gohel DJ. Drug utilization study in ophthalmology outpatients in a tertiary care hospital. Advances in Pharmacology and Pharmacy. 2016;4(2):11-5.

14. Rawah MA, Alkhayri MM, Alomari MA, ALmalki RK, et al. Drug prescription in ophthalmology. Egypt J of Hosp Med. 2017;69(7):2856-9.

15. Prathap SA, Radhika MS, Rai RK. Prescribing pattern of ophthalmological medication in geriatric inpatients of a tertiary care hospital. Int J Basic Clin Pharmacol. 2019;8(5):940-4.

16. Slathia A, Gupta V, Nanda R, Mahajan P. Drug utilization pattern in ophthalmology: A observational and cross-sectional study. Int J Sci Stud. 2017; 5(5):63-5.

17. Dhami DB, Thapa BB, Neupane GP. Prescribing pattern and drug use in ophthalmology out patient department of Nepalgunj Medical College, Nepalgunj, Nepal. JNGMC. 2017;15(2):29-32.

18. Suman RK, Gore VS, Mohanty IR, Israni N, Deshmukh YA. Drug utilization patterns of drugs used in ophthalmology out- patients department at tertiary care hospital. World J Pharm Res. 2015;4(6):2162-70.

19. Yasmeen M, Prabhu B, Vidyashree A. A Drug utilization study in the ophthalmology department of a medical college, Karnataka, India. J Clin Diagn. 2011;5(1):82-4.

20. Yadav P. Drug use in ophthalmology outpatient department: A prospective study at a tertiary care teaching hospital. Indian J Pharm Pract. 2012;5(2):44-8.

21. Jadhav PR, Moghe VV, Deshmukh YA. Drug utilization study in ophthalmology outpatients at a tertiary care teaching hospital. ISRN Pharmacol. 2013;2013:15.

22. Prajwal P, Rai M, Kumar KS, Bhat US, Dsouza FV. Drug utilization pattern in ophthalmology department at a tertiary care hospital. Int Res J Pharm. 2013;4(8):205-10.

23. Bhatt JH, Verma S, Bagde S, Sane RM, Shahani S. Drug utilization study in ophthalmology in OPD patients at a tertiary care teaching hospital. Int J Basic Clin Pharmacol. 2018;7(2):315-8.

24. Akram MF, Shamsheer RP, Krishnan DG, Raju GJKP, Pawar TA. Drug prescribing pattern in ophthalmology outpatient department of a Medical College. Int Arch Bio Med Clin Res. 2016;2(4):17-20. 